Pesq. Vet. Bras. 37(7):667-675, julho 2017

DOI: $10.1590 / \mathrm{S} 0100-736 \mathrm{X} 2017000700003$

\title{
Atividade antiviral e virucida de extratos hidroalcoólicos de própolis marrom, verde e de abelhas Jataí (Tetragonisca angustula) frente ao herpersvírus bovino tipo 1 (BoHV-1) e ao vírus da diarreia viral bovina (BVDV) ${ }^{1}$
}

\author{
Cristina Mendes Peter ${ }^{2 *}$, Tony Picoli ${ }^{3}$, João Luiz Zani ${ }^{4}$, Giulia Soares Latosinski ${ }^{5}$, \\ Marcelo de Lima ${ }^{4}$, Gilberto DÁvila Vargas ${ }^{4}$, Silvia de Oliveira Hübner ${ }^{4}$ \\ e Geferson Fischer ${ }^{4}$
}

\begin{abstract}
Peter C.M., Picoli T., Zani J.L., Latosinski G.S., Lima M., Vargas G.D., Hübner S.O. \& Fischer G. 2017. [Antiviral and virucidal activity of hydroalcoholic extracts of propolis brown, green and jataí bees (Tetragonisca angustula) against Bovine Herpesvirus Type-1 (BoHV-1) and Bovine Viral Diarrhea Virus (BVDV).] Atividade antiviral e virucida de extratos hidroalcoólicos de própolis marrom, verde e de abelhas jataí (Tetragonisca angustula) frente ao Herpersvírus Bovino tipo 1 (BoHV-1) e ao Vírus da Diarreia Viral Bovina (BVDV). Pesquisa Veterinária Brasileira 37(7):667-675. Departamento de Veterinária Preventiva, Universidade Federal de Pelotas, Campus Capão do Leão, Avenida Eliseu Maciel s/n, Jardim América, Capão do Leão, RS 96900-010, Brazil. E-mail: cristina_peter@hotmail.com

Among the biological properties of propolis, the antimicrobial activity has received prominent attention. In this paper, we describe the antiviral and virucidal effect of three hydroalcoholic extracts of propolis (brown, green and jataí bees (Tetragonisca angustula), against bovine herpesvirus type-1 (BoHV-1) and bovine viral diarrhea Virus (BVDV). All hydroalcoholic extracts were obtained from ethanol extraction. The chemical composition of propolis extracts was determined by high-performance liquid chromatography coupled to mass spectrometer (UFLC-PDA-ESI-TOF/MS) to identify and quantify compounds such as caffeic acid and p-coumaric acid, chlorogenic acid, ferulic, and flavonoids such as rutin. Cell toxicity and antiviral activity of propolis extracts in monolayers of MDBK cells (Madin-Darby Bovine Kidney) were assessed by microscopic observation and quantified by the MTT assay (3- (4.5 dimethylthiazol-2yl) -2- 5-diphenyl-2H-tetrazolato bromine). Propolis extract from Jataí bees proved to be less cytotoxic $(1.57 \mathrm{mg} / \mathrm{ml})$ when compared to green extracts $(0.78 \mathrm{mg} / \mathrm{ml})$ and brown $(0.39 \mathrm{mg} / \mathrm{mL})$. Regarding antiviral activity, propolis has shown greater efficacy in both cellular treatments (post and pre-exposure) against BoHV1 when compared to other extracts, ie, there was increased cell viability compared to cell and virus controls. Extracts from Jataí showed activity against both viruses (BoHV-1 and BVDV) infection in the pre-test, whereas brown propolis demonstrated action only against the BoHV-1 in the pre-infection method. To determine the virucidal activity, it were used different dilutions of virus, as well as different temperatures and incubation times. The green propolis at $37^{\circ} \mathrm{C}$ led to a greater reduction in viral titer $\left(4.33_{\text {log }}\right)$ compared to brown $\left(3.5_{\text {log }}\right)$ and jataí $\left(3.24_{\log }\right)$. Jataí propolis showed the best results in both temperatures $\left(22^{\circ} \mathrm{C}\right.$
\end{abstract}

\footnotetext{
${ }^{1}$ Recebido em 20 de junho de 2016.

Aceito para publicação em 21 de novembro de 2016.

2 Doutoranda do Programa de Pós-Graduação em Veterinária, Universidade Federal de Pelotas (UFPel), Campus Capão do Leão, Avenida Eliseu Maciel s/n, Capão do Leão, RS 96900-010, Brasil. *Autor para correspondência: cristina_peter@hotmail.com

${ }^{3}$ Pós-Doutorando do Programa de Pós-Graduação em Veterinária, UFPel, Campus Capão do Leão, Av. Eliseu Maciel s/n, Capão do Leão, RS 96900-010, Brasil.
} 
and $37^{\circ} \mathrm{C}$ ) when tested against BVDV. In summary, the evaluated extracts showed antiviral and virucidal activity against BoHV-1 and BVDV, and may be important targets for the development of new compounds as an alternative to commercial antivirals.

INDEX TERMS: Antiviral activity, virucidal activity, hydroalcoholic extracts, propolis, bees, Tetragonisca angustula, bovine herpesvirus type-1, Bovine Viral Diarrhea Virus, BVDV, BoHV-1, chemical analysis, cytotoxicity, alternative treatment.

RESUMO.- Dentre as propriedades biológicas da própolis, a atividade antimicrobiana tem merecido destacada atenção. No presente trabalho, descreve-se a ação antiviral e virucida de três extratos hidroalcoólicos de própolis (marrom, verde e de abelhas jataí (Tetragonisca angustula), frente ao Herpesvírus Bovino tipo (BoHV-1) e ao Vírus da Diarreia Viral Bovina (BVDV). Os três extratos hidroalcoólicos foram obtidos de extração etanólica e são oriundos do sul do Brasil. A composição química dos extratos de própolis foi determinada pela cromatografia líquida de alta eficiência acoplada a espectrômetro de massas (UFLC-PDA-ESI-TOF/ MS) que identificou e quantificou compostos como: ácido cafeico e ácido p-cumárico, ácido clorogênico, ácido ferúlico, além de flavonoides como a rutina. A toxicidade celular bem como a atividade antiviral dos extratos de própolis em monocamadas de células MDBK (Madin-Darby Bovine Kidney) foi avaliada através de observação microscópica e quantificada pelo teste de MTT (3-(4,5 dimetiltiazol-2yl)-2-5 -difenil-2H tetrazolato de bromo). 0 extrato de própolis de abelhas jataí demonstrou ser menos citotóxico $(1,57 \mu \mathrm{g} /$ $\mathrm{mL})$, quando comparado aos extratos verde $(0,78 \mu \mathrm{g} / \mathrm{mL})$ e marrom $(0,39 \mu \mathrm{g} / \mathrm{mL})$. Quanto a atividade antiviral, a própolis verde demostrou maior eficácia em ambos os tratamentos celulares (pós e pré-exposição) frente ao BoHV-1 em relação aos outros extratos, ou seja, houve maior viabilidade celular quando comparada aos controles de células e vírus. Já a de jataí apresentou atividade frente aos dois vírus (BoHV-1 e BVDV) no método pré-infecção, enquanto a própolis marrom demonstrou ação apenas frente ao BoHV1 também no método pré-infecção. Para determinação da atividade virucida foram utilizadas diferentes diluições dos vírus, bem como temperaturas e tempos distintos de incubação. A própolis verde a $37^{\circ} \mathrm{C}$ propiciou a maior redução no título viral $\left(4,33_{\log }\right)$ em relação a marrom $\left(\log =3,5_{\text {log }}\right)$ e de jataí $\left(\log =3,24_{\log }\right)$. No entanto, frente ao BVDV a própolis jataí apresentou os melhores resultados em ambas as temperaturas $\left(22^{\circ} \mathrm{C}\right.$ e $\left.37^{\circ} \mathrm{C}\right)$. Portanto, os extratos avaliados apresentaram atividade antiviral e virucida frente ao BoHV-1 e BVDV, o que os torna alvo para o desenvolvimento de novos biofármacos como alternativa ao uso de antivirais comerciais em Medicina Veterinária.

TERMOS DE INDEXAÇÃO: Atividade antiviral, atividade virucida, extrato hidroalcoólico, própolis, abelhas jataí, Tetragonisca angustula, Herpersvírus Bovino tipo 1, Vírus da Diarreia Viral Bovina, BVDV, BoHV-1, composição química, citotoxicidade, tratamento alternativo.

\section{INTRODUÇÃO}

A busca por recursos genéticos e bioquímicos que possam ser transformados ou que contenham moléculas bioativas com potencialidade terapêutica tem sido alvo de intensas investigações que contemplam produtos naturais (Bastos et al. 2011). Ainda que esses estudos demonstrem a atividade biológica, principalmente de produtos vegetais, outras substâncias como a própolis tem conquistado espaço significativo na busca por alternativas à utilização de fármacos comerciais e, consequentemente, a formulação de novas drogas com a utilização da própolis (Bastos et al. 2011, Bankova et al. 2014).

A própolis é uma substância resinosa, produzida pelas abelhas a partir do exsudato de diversas partes das plantas, como cascas e botões florais (Bankova \& Marcucci 2000). Esses constituintes são biotransformados pela adição de cera e pela ação da enzima 13-glicosidase, produzida nas glândulas salivares das abelhas (Bastos et al. 2011). A composição química da própolis é resultante, principalmente, das características fitogeográficas existentes ao redor da colmeia (Bankova et al. 1998), como as plantas fornecedoras de resina, bem como da espécie de abelha coletora. Esta característica reflete na diversidade de atividades biológicas e farmacêuticas apresentadas por este produto.

Na literatura observa-se que grande parte dos trabalhos científicos sobre as atividades terapêuticas e biológicas da própolis estão associadas à espécie de abelha Apis mellifera, pertencente à família Apidae. No entanto, estudos utilizando a própolis de origem de abelhas sem ferrão têm sido descritos, demonstrando seu potencial terapêutico, como a atividade antimicrobiana (Ortega et al. 2011, Choudhari et al. 2012), antioxidante (Sawaya et al. 2009) e antitumoral (Gilberto et al. 2012). Além disso, entre as atividades biológicas da própolis de Apis mellifera, destacam-se a antibacteriana (Cabral et al. 2009, Ortega et al. 2011), antiviral (Fischer et al. 2007, Cueto et al. 2011), antifúngica (Salomão et al. 2008, Jug et al. 2014) e antiparasitária (Gressler et al. 2012). Esse potencial biológico atribui-se a um sinergismo que ocorre entre os constituintes presentes na sua constituição (Pinto et al. 2001), como os compostos flavonoides, ácidos fenólicos e seus ésteres (Bankova \& Marcucci 2000).

Estudos sobre a atividade antiviral da própolis e seus derivados já foram descritos frente a vírus de importância em medicina e medicina veterinária como o herpes vírus humano tipo 1 (HSV1) (Amoros et al. 1992, Coelho et al. 2015, Yildirim et al. 2016) e dois (Vynograd et al. 2000, Yildirim et al. 2016), vírus da imunodeficiência humana (HIV) (Gekker et al. 2005), vírus da influenza aviária (Kujumgiev 1999), Herpes Vírus Bovino (BoHV-5) (Fischer et al. 2007) e o Parvovírus Suíno (PPV) (Ma et al. 2015) e demonstraram resultados promissores da própolis frente a vírus patogênicos para humanos e animais.

0 presente estudo descreve a atividade antiviral e virucida de três extratos hidroalcoólicos de própolis de diferentes origens geográficas frente ao BoHV-1 e ao BVDV. Os resultados demonstram expressiva atividade contra es- 
ses vírus, apresentando-se como uma alternativa natural a prevenção e ao tratamento das enfermidades ocasionadas por eles.

\section{MATERIAL E MÉTODOS}

Os experimentos foram conduzidos no Laboratório de Virologia e Imunologia da Universidade Federal de Pelotas, em colaboração com o Laboratório de Cromatografia e Espectrometria de Massas - LACEM da Universidade Federal de Pelotas.

Própolis. As amostras da própolis marrom foram adquiridas comercialmente da Cooperativa de Apicultores e Fruticultores da Região Sul, localizada no Município de Pelotas, RS; a própolis verde foi adquirida da empresa Néctar Farmacêutica ${ }^{\circledR}$ Ltda, Santa Cartarina, enquanto que a própolis de abelhas jataí foi obtida de um meliponário localizado no município de Morro Redondo, Rio Grande do Sul.

Preparação dos extratos hidroalcoólicos. Os extratos hidroalcoólicos foram preparados conforme (Paulino et al. 2002). As amostras de própolis foram congeladas a $-70^{\circ} \mathrm{C}$ para posterior trituração. A extração foi realizada em solução contendo álcool $96^{\circ}$ GL na proporção de uma parte de própolis para três partes de álcool, sob agitação por 24 horas, a $37^{\circ} \mathrm{C}$. Após, o solvente foi evaporado e a matéria seca resultante foi dissolvida em tampão fosfato $(\mathrm{pH} 7,2)$ e emulsificada utilizando EUMULGIN ${ }^{\circledR}$ HRE-40, para obtenção da concentração final de $100 \mathrm{mg} / \mathrm{mL}$. A esterilização do composto foi realizada em filtro hidrofílico com porosidade de $22 \mu \mathrm{m}$. Após, foi realizada diluição com água destilada estéril até a concentração de uso.

\section{Análise da composição química dos extratos de própolis \\ UFLC-PDA-ESI-TOF/MS instrumentação e condições. A} composição química dos extratos de própolis foi determinada por cromatografia líquida acoplada à espectrometria de massas. Para isso, dez microlitros dos extratos foram injetados em cromatógrafo líquido de ultra-alta eficiência (Shimadzu, Prominence) acoplado a espectrômetro de massas de alta resolução (tipo quadrupolo-tempo de vôo) (MicrOTOF-Q, Bruker Daltonics). Os compostos fenólicos foram separados utilizando pré-coluna C18 (2,0x4mm) e coluna Luna C18 (2,0x150mm, $100 \AA$, 3um) Phenomenex (Torrance, CA, USA), sendo solução de ácido fórmico em água $(0,1 \%$ $\mathrm{v} / \mathrm{v}$, eluente A) e metanol (eluente B) usadas como fase móvel, com fluxo de $0,2 \mathrm{~mL}$ min- 1 e temperatura da coluna a $40^{\circ} \mathrm{C}$. 0 gradiente de eluição foi: 0-2 min, 10\% B, 2-15 min, 10-75\% B, 15-30 $\min , 75 \%$ B, 30-32 $\min 75-10 \%$ B, 32-40 min, 10\% B. 0 detector PDA foi definido para digitalizar no intervalo $210-800 \mathrm{~nm}$. O espectrômetro de massas foi operado no modo ESI negativo, com voltagem do capilar em $4000 \mathrm{~V}$, pressão do gás de nebulização (N2) de 2 bar, gás de secagem em $8 \mathrm{~L} / \mathrm{min}$ e temperatura da fonte de $180^{\circ} \mathrm{C}$, usando os parâmetros padrões do equipamento. 0 equipamento foi calibrado com formiato de sódio $10 \mathrm{mM}$, cobrindo toda a faixa de aquisição (de m/z 50 até 1200). Os espectros de massa foram processados utilizando o software Data Analysis 4.0 (Bruker Daltonics).

Quantificação de compostos fenólicos. Para quantificação dos compostos fenólicos e flavonoides dos extratos de própolis foram preparadas curvas de calibração utilizando os padrões externos: ácido gálico, catequina, ácido 4-hidroxibenzoico, ácido clorogênico, epitequina, ácido cafeico, ácido vanilico, ácido siringico, ácido p-cumárico, ácido ferúlico, rutina, ácido elágico, miricetina, quercetina, hesperetina, kaempferol, luteolina, apigenina, pinocembrina, crisina e galangina, nas concentrações variando de 0 a $10 \mathrm{ug} / \mathrm{mL}$. Os compostos fenólicos presentes nas amostras foram caracterizados pela sua UV/Vis (220-800nm), os tempos de retenção em relação aos padrões externos e os espectros de massa.

\section{Ensaios da atividade antiviral}

Células e vírus. Células da linhagem MDBK (Madin-Darby Bovine Kidney) foram mantidas em meio essencial mínimo (E-MEM, Sigma-Aldrich ${ }^{\circledR}$, USA) suplementado com soro fetal bovino (SFB, Gibco $^{\circledR}$, USA), penicilina (Sigma-Aldrich ${ }^{\circledR}$, USA), estreptomicina (Vetec $^{\circledR}$, Brasil), enrofloxacina (Bayer ${ }^{\circledR}$, Brasil) e anfotericina B (Cristália ${ }^{\circledR}$, Brasil). As células foram cultivadas em placas de poliestireno de 96 cavidades (KASVI ${ }^{\circledR}$, Brasil) a $37^{\circ} \mathrm{C}$ em um ambiente com $5 \%$ de $\mathrm{CO}_{2}$ para estabelecimento da monocamada. Esta linhagem foi selecionada por ser permissível aos vírus utilizados no estudo.

As atividades antiviral e virucida dos extratos de própolis foram avaliadas frente ao BoHV-1 (cepa Los Angeles) e BVDV (cepa Singer), pertencentes ao Laboratório de Virologia e Imunologia, UFPel.

Toxicidade celular. Em monocamadas de células MDBK foram adicionadas diferentes concentrações dos extratos de própolis: $1000,100,50,25,12,5,6,25,3,12,1,56,0,78,0,39,0,19$ e $0,09 \mu \mathrm{g}$ $/ \mathrm{mL}^{-1}$. A viabilidade celular foi avaliada pela observação microscópica diária das alterações morfológicas das células, e mensurada pelo teste de MTT (3-(4,5 dimetiltiazol-2yl)-2-5-difenil-2H tetrazolato de bromo) após $72 \mathrm{~h}$ de incubação Mossmann (1983). A citotoxicidade foi expressa como concentração citotóxica $90 \%$ (CC90\%): concentração capaz de inibir 90\% do cultivo celular em comparação com as células não tratadas. Os testes foram realizados em quadruplicata e repetidos três vezes em dias alternados.

Ensaio da atividade antiviral. Os títulos virais estão expressos como doses infectantes para $50 \%$ de cultivos celulares (TCID50) e a atividade antiviral foi expressa em percentual de inibição (PI) e calculada através dos títulos virais pela fórmula:

$$
\left[1-\left(\frac{\text { antilog tratamento }}{\text { antilog controle }}\right)\right] \times 100
$$

A atividade antiviral foi avaliada através de dois métodos distintos de tratamento das células com os extratos: método I sobre um tapete pré-formado de células o vírus foi inoculado e, após uma hora, os extratos foram adicionados; método II - extratos foram mantidos em contato com as células e, após 24 horas, as cepas de vírus foram inoculadas. Ambas as cepas virais foram inoculadas em concentração de 0,1 MOI. Todos os extratos foram utilizados em quatro concentrações distintas (duas acima e duas abaixo da contração tóxica). Assim, foram utilizadas 3,$12 ; 1,56$; 0,$78 ; 0,39 \mu \mathrm{g} / \mathrm{mL}-1$ do extrato de abelhas jataí e 1,$56 ; 0,78 ; 0,39$; $0,19 \mu \mathrm{g} / \mathrm{mL}-1$ de extrato das própolis marrom e verde.

A mensuração da atividade antiviral dos extratos de própolis foi realizada após $72 \mathrm{~h}$ de incubação das células a $37^{\circ} \mathrm{C}$, através da viabilidade celular, pelo método MTT. Nessas condições, foi determinada a concentração efetiva a 50\% (CE50), que representa a concentração do extrato de própolis capaz de inibir o efeito citopático do vírus em 50\%. 0 ensaio foi realizado em sextoplicata.

Ensaio da atividade virucida. A atividade virucida foi avaliada incubando-se as cepas de vírus com concentrações não tóxicas dos diferentes extratos de própolis: $3,9 \mu \mathrm{g} / \mathrm{mL}^{-1}$ para própolis marrom e verde, e $7,8 \mu \mathrm{g} / \mathrm{mL}^{-1}$ para própolis de abelhas jataí. Em todas as situações, os tempos de incubação foram de $0,1,2,4$, 8 e 24 horas, em temperaturas de $22^{\circ} \mathrm{C}$ ou $37^{\circ} \mathrm{C}$. Como controle negativo utilizou-se tampão fosfato-salino (PBS) associado aos extratos de própolis e como controle positivo, PBS associado aos vírus. Após as incubações, as suspenções de vírus e extrato foram tituladas pelo método (Mayr et al. 1982).

A avaliação da atividade virucida também foi realizada através da viabilidade celular, pela observação microscópica das alterações morfológicas das células e quantificadas por meio do cálculo da Dose Infectante 50\% (Reed \& Muench 1938).

Análises estatísticas. Para avaliação da atividade antiviral e virucida dos três extratos de própolis foi realizado a Análise de 
Variância (ANOVA) e teste de comparação entre médias pelo teste Tukey. Foi usado o Software Bioestat $5.3^{\circledR}$.

\section{RESULTADOS}

\section{Análises cromatográficas}

Através da cromatografia líquida acoplada a espectrometria de massas em modo negativo (ESI negativo), a análise qualitativa e quantitativa dos extratos testados está expressa no (Quadro 1). Dos 21 compostos padrão testados, 15 foram identificados em todos os extratos de própolis 0 ácido p-cumárico foi o composto majoritário nas três amostras de própolis, sendo altamente quantificada na própolis verde $(52,09 \mathrm{mg} / \mathrm{mL})$, seguido da quantificação dos compostos rutina e ácido clorogênico para todos os extratos.

\section{Toxicidade celular dos extratos de própolis}

Os valores obtidos da toxicidade celular em Células MDBK dos três extratos hidroalcoólicos da própolis estão expressos através das medianas das diferentes concentrações utilizadas (Fig.1). Nas menores concentrações testadas $(0,097$ a $0,39 \mu \mathrm{g} / \mathrm{mL})$, todos os extratos não apresentaram citotoxicidade em relação ao controle celular. A partir da concentração de $0,78 \mu \mathrm{g} / \mathrm{mL}$, a citotoxicidade foi observada nos extratos de própolis marrom (PM) e verde (PV), ao passo que para o própolis jataí (PJ), a mesma foi observada na concentração de $1,57 \mu \mathrm{g} / \mathrm{mL}$.

\section{Ensaio da atividade antiviral}

Os extratos de própolis foram adicionados após inoculação viral sobre as células MDBK (método I), ou antes, da inoculação viral (método II). Nas avaliações feitas com o BoHV-1, atividade antiviral pôde ser observada quando os extratos foram acrescentados às células MDBK antes da inoculação viral (Fig.2C), o que permitiu maior percentual de células viáveis.

Nessa análise, quanto maior o percentual de células viáveis, menor a replicação viral, ou seja, maior ação antiviral dos compostos avaliados. A própolis marrom, neste caso, numa concentração de $0,19 \mu \mathrm{g} / \mathrm{ml}$, permitiu viabilidade de $90 \%$ das células, resultado estatisticamente superior $(\mathrm{P}<0,01)$ aos demais tratamentos e ao controle de células e vírus. A inoculação do BoHV-1 nas células com posterior inoculação dos diferentes extratos de própolis não resultou em efeito antiviral (Fig.2A), sugerindo que o vírus, uma vez no interior da célula, não é destruído. É possível, portanto, que ao inocular-se a própolis previamente ao vírus em células da linhagem MDBK, este extrato torne a célula refratária ao vírus, impedindo a sua penetração, através da modificação de receptores de superfície, por exemplo. Ainda, outro mecanismo que pode explicar os resultados deste estudo é de que ao entrar em contato com a própolis sobre as células, o vírus seja destruído antes mesmo de penetrar a célula.

Quadro 1. Análise qualitativa e quantitativa $(\mathrm{mg} / \mathrm{g})$ dos extratos hidroalcoólicos de própolis verde, marrom e de abelhas jataí por cromatografia líquida acoplada a espectrometria de massas em modo negativo (ESI negativo)

\begin{tabular}{|c|c|c|c|c|c|}
\hline $\begin{array}{l}\text { Composição Química } \\
\text { e respectivo grupo }\end{array}$ & $\begin{array}{l}\mathrm{m} / \mathrm{z}- \\
{[\mathrm{M}-\mathrm{H}]}\end{array}$ & $\begin{array}{l}\text { Tempo de Retenção } \\
\text { (minutos) }\end{array}$ & $\begin{array}{l}\text { Própolis } \\
\text { verde }\end{array}$ & $\begin{array}{l}\text { Própolis } \\
\text { marrom }\end{array}$ & $\begin{array}{l}\text { Própoli } \\
\text { Jataí }\end{array}$ \\
\hline \multicolumn{6}{|l|}{ Ácido fenólico } \\
\hline \multicolumn{6}{|l|}{ Derivados do Ácido benzoico } \\
\hline Ácido galico & 169.0132 & 5.41 & n.d. & n.d. & n.d. \\
\hline Ácido 4-Hydroxybenzoico & 137.0233 & 11.17 & + & + & + \\
\hline Ácido siringico & 197.0445 & 12.45 & n.d. & + & n.d. \\
\hline Ácido vanílico & 167.0339 & 12.12 & n.d. & + & n.d. \\
\hline \multicolumn{6}{|c|}{ Derivados do Ácido Hydroxycinamico } \\
\hline Ácido cafeico & 179.0338 & 12.05 & 0.61 & 0.17 & + \\
\hline Ácido clorogênico & 353.0867 & 11.27 & 0.96 & 0.36 & 0.26 \\
\hline Ácido p-Coumarico & 163.0390 & 13.67 & 52.09 & 3.39 & 6.6 \\
\hline Ácido ferúlico & 193.0495 & 14.01 & 0.64 & 0.20 & 0.09 \\
\hline \multicolumn{6}{|c|}{ Derivados do Ácido Hydroxydiphenico } \\
\hline Ácido elágico & 300.9978 & 15.21 & + & + & + \\
\hline \multicolumn{6}{|l|}{ Flavonoide } \\
\hline \multicolumn{6}{|l|}{ Flavanone } \\
\hline Catequina & 289.0707 & 10.25 & n.d. & n.d. & n.d. \\
\hline Hesperetina & 301.0707 & 17.33 & + & + & + \\
\hline Pinocembrina & 255.0652 & 19.49 & + & + & + \\
\hline \multicolumn{6}{|l|}{ Flavone } \\
\hline Apigenina & 269.0445 & 18.24 & + & + & + \\
\hline Crisina & 253.0495 & 20.12 & + & + & + \\
\hline Luteolina & 285.0394 & 17.30 & + & + & + \\
\hline \multicolumn{6}{|l|}{ Flavonol } \\
\hline Epicatequina & 289.0707 & 11.74 & n.d. & n.d. & n.d. \\
\hline Galangina & 269.0444 & 20.53 & + & + & + \\
\hline Kaempferol & 285.0393 & 18.00 & + & + & + \\
\hline Myricetina & 317.0292 & 15.52 & n.d. & n.d. & n.d. \\
\hline Quercetina & 301.0343 & 16.89 & + & + & + \\
\hline Rutina & 609.1450 & 14.64 & 3.71 & 0.81 & 0.65 \\
\hline
\end{tabular}

+ Detectável, porém não quantificado, n.d. = não detectável e não quantificado. 


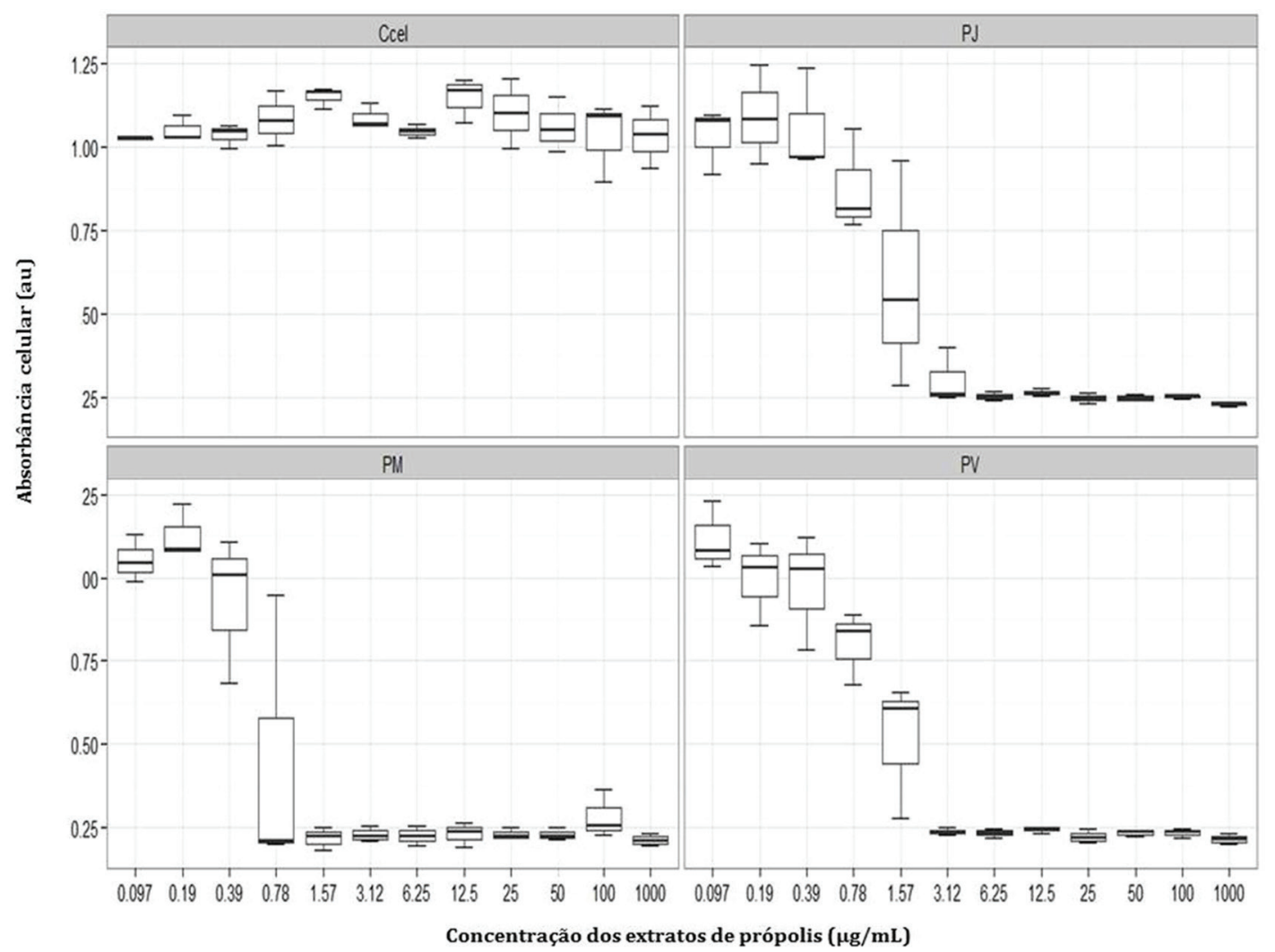

Fig.1. Citotoxicidade dos extratos de própolis marrom (PM), própolis verde (PV) e de abelhas jataí (PJ) frente a células MDBK (Contdecel).
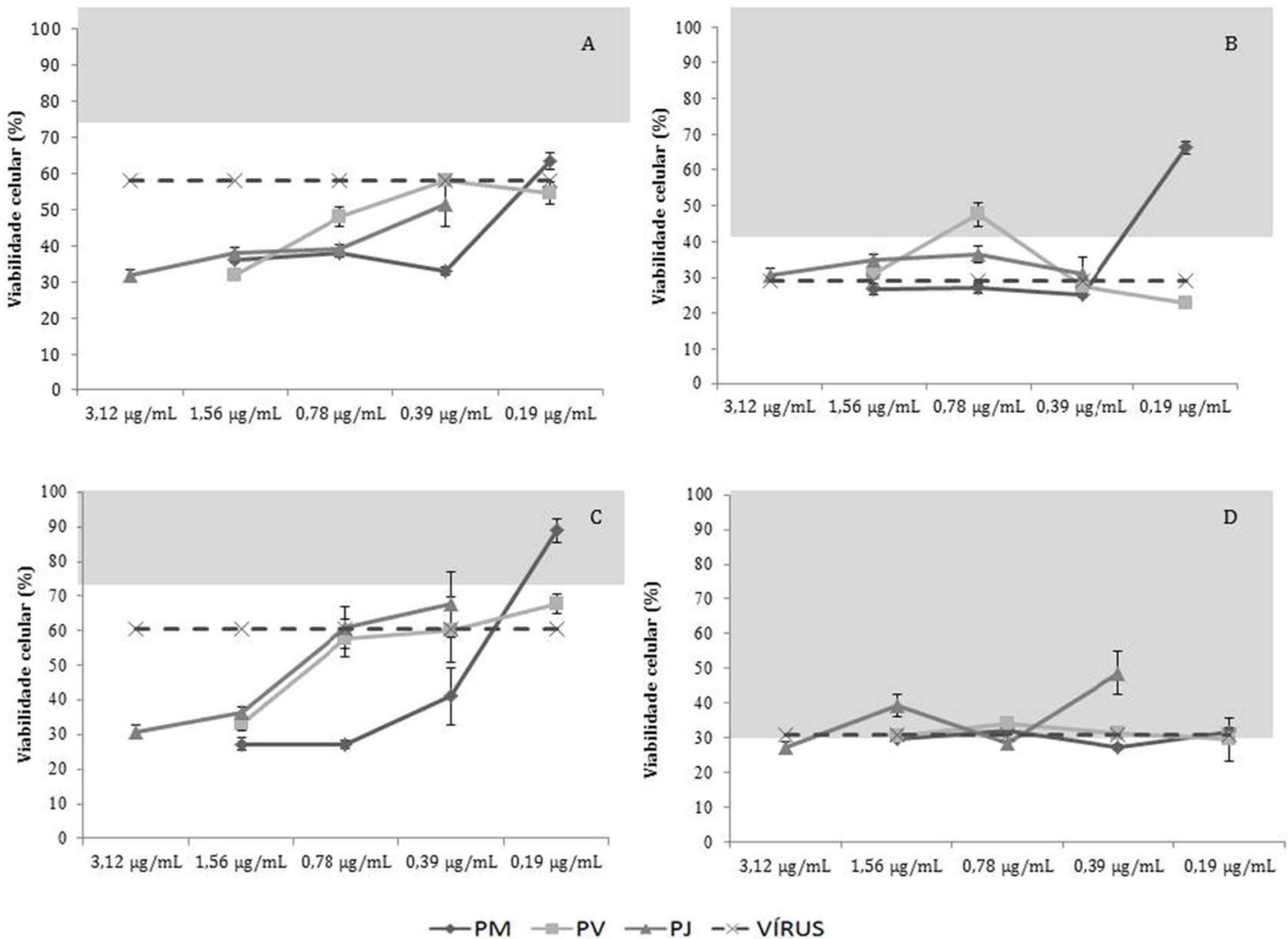

$\rightarrow-P J-\times$ VÍRUS

Fig.2. Efeito antiviral dos Extratos de própolis sob dois métodos distintos de infecção (Método I = após inoculação viral e Método II = antes da inoculação viral), frente ao BoHV-1 e ao BVDV; Método I (Fig.2A = BoHV-1 e Fig.2B = BVDV); Método II (Fig.2 C = BoHV-1 e Fig.2D = BVDV). Valores obtidos dentro do espaço cinza (dois desvios padrão acima da linha pontilhada (células e vírus), significam ação antiviral significativa $(\mathrm{P}<0,01)$. 

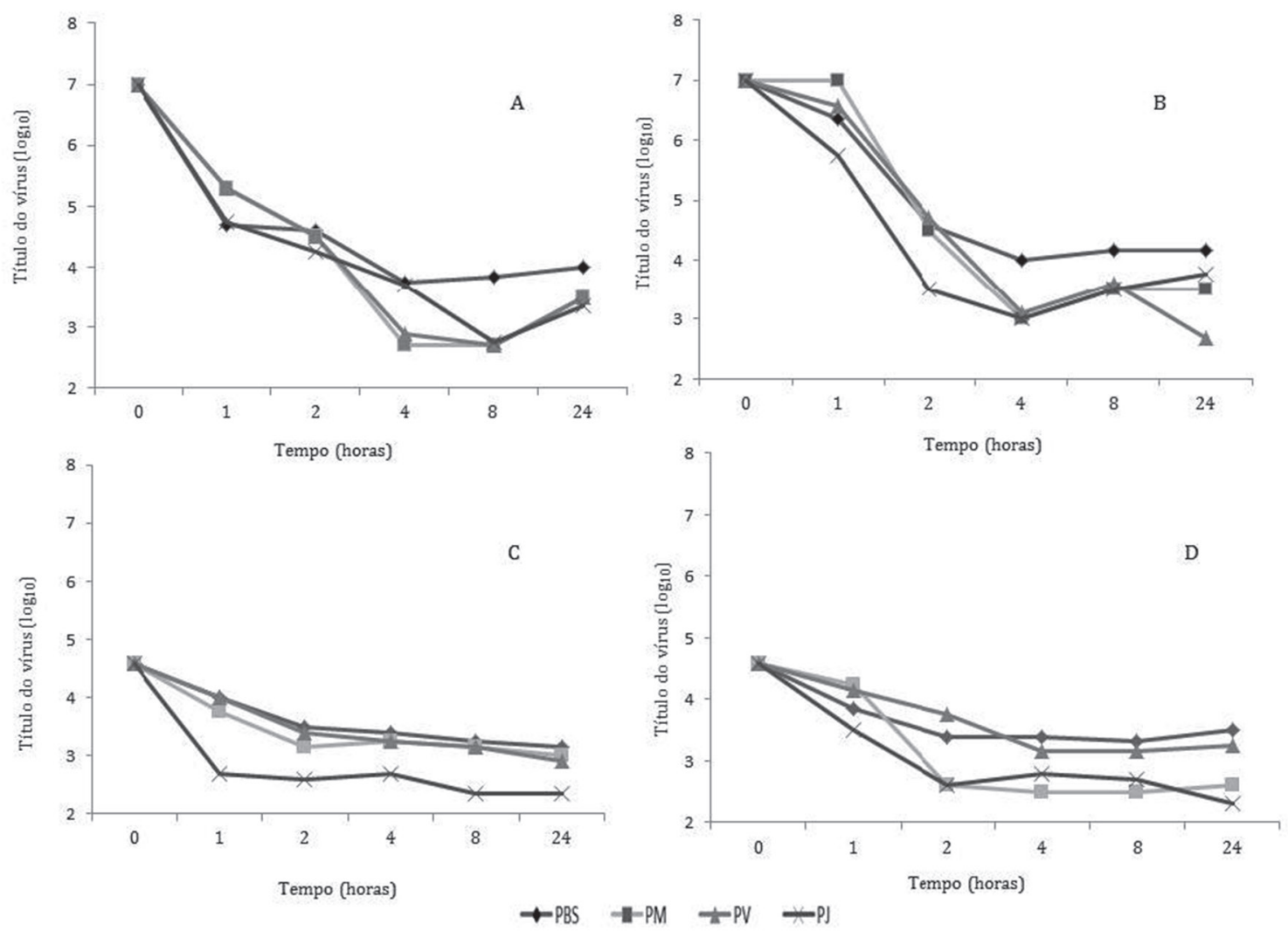

Fig.3. Atividade virucida dos extratos de Própolis Marrom (PM), Própolis Verde (PV) e Própolis Jataí (PJ) frente ao Herpes vírus bovino tipo 1 (BoHV-1) a 22 e $37^{\circ} \mathrm{C}(\mathbf{A})$ e (B) e ao Vírus da Diarreia Viral Bovina 22 e $37^{\circ} \mathrm{C}$ (C) e (D), respectivamente.

\section{Ensaio da atividade virucida}

Atividades biológicas importantes são conferidas à própolis brasileira, como por exemplo, a atividade virucida de extratos etanólicos, atribuída principalmente à presença de ácidos fenólicos como Ácido p-cumárico, Artepillin C e derivados do ácido cinâmico (Akao et al. 2003).

Os valores obtidos da atividade virucida das amostras de própolis estão expostos na (Fig.3). Quando o vírus estudado foi o BoHV-1, mantido por até 24 horas em temperatura de $22^{\circ} \mathrm{C}$, não se observou efeito virucida de nenhum dos extratos avaliados, ao final das 24 horas de observação. No entanto, quando a temperatura foi de $37^{\circ} \mathrm{C}$, após 24 horas de incubação do vírus com os diferentes extratos, a própolis verde proporcionou redução de $(1,5 \mathrm{log})$ em relação ao controle PBS, passando de $(\log 4,16)$ para $(\log 2,66)$. Os extratos de própolis marrom e de jataí também demonstraram efeito virucida, reduzindo o título do vírus para (log $3,5)$ e $(3,76)$, respectivamente.

\section{DISCUSSÃO}

Bankova \& Marcucci 2000 descrevem que o perfil químico da própolis de A. mellifera varia conforme sua região de origem. As própolis marrom, verde e de abelhas jataí no presente estudo são oriundas da região sul do Brasil, regiões fitogeográficas semelhantes, fato que justifica a semelhança na composição química qualitativa entre as três amostras estudas. No entanto, a própolis jataí não apresentou ácido cafeico em sua composição, e quanto à análise quantitativa apresentou valores inferiores quando comparados a verde e marrom, respectivamente.

Sawaya et al. (2004) avaliaram a composição de própolis utilizando amostras de Apis mellifera e Tetragonisca angustula de diferentes regiões do Brasil, observaram, por cromatografia líquida de alta eficiência (CLAE), que a amostra produzida por T. angustula obteve composição química semelhante ao de Apis melífera. No entanto, os autores observaram diferença na composição entre as amostras produzidas por Apis mellifera, variando de acordo com a região de coleta. Resultados estes semelhantes ao do presente trabalho, uma vez que as amostras apresentaram similaridade na avaliação qualitativa, e as própolis verde e marrom oriundas de A. mellífera, apresentaram significativa diferença na quantificação dos compostos encontrados.

Embora as própolis verde e marrom produzidas pela $A$. mellifera tenham apresentado semelhança química, observou-se a detecção do ácido siríngico e ácido vanílico somente na própolis marrom, os quais variaram em decorrência da região de coleta. Em relação à própolis jataí, a principal fonte vegetal é a Schinus terebinthifolius, popularmente conhecida por "aroeira vermelha" (Sawaya et al. 2004) e, por ser de ampla distribuição no Brasil, também é utilizada como de fonte para a elaboração das demais própolis, como a verde, o que contribui para a semelhança na composição química de ambas amostras.

Pereira et al. (2003) avaliaram a composição química de extratos etanólicos de várias amostras de própolis de 
T. angustula e A. mellifera dos Estados do Paraná e Minas Gerais através da CLAE: identificaram altas concentrações de ácido fenólicos como os derivados do ácido cinâmico e ácido p-cumárico nas própolis oriundas de A. mellífera. Entretanto, nas amostras de própolis de T. angustula, foram identificadas baixas concentrações destes compostos.

Os resultados do efeito citotóxico dos extratos de própolis marrom, verde e de jataí utilizados no presente estudo são distintos com os dados encontrados na literatura, uma vez que as concentrações não tóxicas obtidas foram superiores aos valores da bibliografia científica (Amoros et al. 1992, Vynograd et al. 2000, Bankova et al. 2014). Ainda que a própolis seja considerada um produto natural e a possível ausência de toxicidade para o homem e animais seja relatada como um de seus benefícios (Vynograd et al. 2000), os resultados demonstram que os extratos avaliados apresentaram toxicidade em células MDBK e a própolis de abelhas jataí demonstrou ser a menos tóxica, enquanto a marrom, altamente tóxica.

Em estudos que avaliam a atividade antiviral utilizando cultivos celulares, deve-se estimar a toxicidade dos compostos em relação às células, uma vez que as concentrações de própolis utilizadas em ensaios antivirais, descritos na literatura, variam desde $5 \%$ até $0,0003 \%$ (Amoros et al. 1992). Estes percentuais equivalem à maior concentração que não promove alterações morfológicas nas células (Vynograd et al. 2000).

Essa maior toxicidade apresentada pelos extratos de própolis do presente trabalho pode ser justificada pela forma de extração utilizada neste estudo (Paulino et al. 2002). Segundo os autores, esta forma de extração remove uma maior quantidade de substâncias bioativas presentes na própolis, fato que justifica esta maior toxicidade dos extratos avaliados frente aos dados de literatura utilizando outras formas de extração que não esta descrita no presente estudo.

Em trabalho semelhante, em que Bankova et al. (2014) avaliaram a atividade antiviral de um extrato hidroalcoólico de própolis canadense, a concentração não citotóxica máxima tolerada da própolis em células MDBK foi de $0,032 \mathrm{mg} / \mathrm{mL}$. Este valor é inferior aos obtidos no presente estudo que foi de $0,097 \mu \mathrm{g} / \mathrm{mL}$ para própolis marrom e verde e $0,39 \mu \mathrm{g} / \mathrm{mL}$ própolis jataí.

Ainda que os mecanismos de ação da própolis sobre os vírus ainda não estejam totalmente elucidados, Bankova et al. (2014) avaliaram um extrato alcoólico de própolis frente ao Herpes simples tipo 2 (HSV2) antes do contato com a célula, e sugerem que a ação da própolis ocorre na estrutura do envelope viral ou modificando componentes estruturais necessários para adsorção ou entrada do vírus na célula. Os mesmos autores, ao avaliarem o mesmo extrato frente a Herpes simples tipo 1 (HSV1), sugerem que o vírus livre apresenta maior sensibilidade à própolis, e descrevem que a administração da própolis antes ou no momento da infecção promove maior efeito de inibição do vírus (Bankova et al. 2014). No presente estudo, dois extratos (própolis marrom e de jataí) também tiveram maior atuação quando inoculadas às células previamente ao vírus.

A análise química por CLAE dos extratos de própolis apresentou semelhança qualitativa entre as amostras, va- riando a quantitativa, uma vez que a própolis verde apresentou maiores concentrações dos compostos químicos quando comparada a marrom e a própolis de abelhas jataí, respectivamente. Estes dados justificam os resultados da eficiência dos extratos frente aos vírus avaliados, pois os compostos identificados e quantificados no presente estudo são descritos na literatura como os principais responsáveis pela atividade antimicrobiana, dentre elas a atividade antiviral e virucida (Duran et al. 2011, Yildirim et al. 2016).

Quando a análise da atividade antiviral dos extratos avaliados se deu frente ao BVDV, a própolis marrom, também na concentração de $0,19 \mu \mathrm{g} / \mathrm{mL}$, demonstrou capacidade antiviral $(\mathrm{P}<0,01)$, mesmo após a inoculação prévia do vírus (Fig.2B), sugerindo a sua destruição no interior da célula. 0 mesmo desempenho não foi observado quando esta amostra de própolis foi inoculada previamente ao BVDV (Fig.2D). No entanto, a inoculação prévia de 0,39 $\mu \mathrm{g} /$ $\mathrm{mL}$ do extrato hidroalcoólico de própolis de abelhas jataí teve efeito pronunciado frente ao BVDV (Fig.2D), com 50\% de viabilidade celular.

A toxicidade dos extratos de própolis estudados apresentou-se variável entre as diferentes amostras analisadas. Por isso, no presente estudo utilizou-se duas concentrações consideradas tóxicas e duas não tóxicas para as células. A consequência disso pode ser observada na mensuração da atividade antiviral, uma vez que este efeito pôde ser observado nas concentrações mais baixas de própolis. É provável que nas concentrações mais altas, a viabilidade celular seja menor por que o próprio extrato, em concentração tóxica, tenha causado a destruição das células.

0 extrato de própolis verde, neste estudo, não demonstrou atividade antiviral significativa em nenhum dos parâmetros analisados. Estes dados diferem daqueles obtidos por Fischer et al. (2007), que avaliaram o efeito da atividade antiviral de uma amostra de própolis verde brasileira frente ao Herpesvírus bovino tipo 1 e BVDV. Os pesquisadores utilizaram duas suspensões de uma amostra de BoHV-1 e de uma amostra de BVDV, que foram incubadas com $1000 \mu \mathrm{g}$ da própolis. 0 tempo de incubação foi de zero e seis horas para a suspensão 1 do BoHV-1 e BVDV, e duas a oito horas para a suspensão 2 do BoHV-1 e BVDV. Como resultados, os autores obtiveram a inativação do BoHV-1 nas duas suspensões, nos tempos de incubação de seis horas e oito horas nas suspensões 1 e 2 , respectivamente. No entanto, frente ao BVDV, não obtiveram resultados significativos. No presente estudo, a ausência de efeito antiviral possivelmente tenha ocorrido pela concentração mais baixa utilizada do extrato.

Cueto et al. (2011) descreveram a atividade antiviral de dois extratos etanólicos de própolis (EP1 e EP2) oriundos de um apiário do município de Santa Maria, Rio Grande do Sul, frente ao Calicivírus felino (FCV), Adenovírus canino tipo 2 (CAV-2) e Vírus da Diarréia Viral Bovina (BVDV). Obtiveram o perfil químico das amostras por meio da CLAE e identificaram a presença de flavonóides como rutina, quercetina e ácido gálico. Além disso, ambos os extratos evidenciaram atividade antiviral frente ao BVDV e CAV-2 quando acrescidos ao cultivo celular anteriormente à inoculação 
viral. Resultado semelhante foi encontrado no presente estudo ao utilizar-se o extrato de jataí que apresentou perfil químico semelhante ao dos autores, e atividade antiviral significativa frente ao BVDV quando no tratamento antes da inoculação viral.

Coelho et al. (2015) avaliaram a ação antiviral de um extrato hidroetanólico de Scaptotrigona postica oriundo da região de Barra de Corda, estado do Maranhão, Brasil frente ao Herpes Simplex Vírus (HSV-1). A análise química da própolis foi realizada por meio de HPLC-DAD-ESI /MS, e a mensuração da atividade antiviral da própolis foi realizada através da quantificação do DNA e microscopia eletrônica. $\mathrm{Na}$ análise química estres pesquisadores encontraram, em maiores quantidades, alcalóides pirrolizidínicos e flavonas C-glicosilo, este composto detectado pela primeira vez em amostra de origem de abelhas melíponas. Também detectaram ação antiviral significativa. A amostra de própolis de Scaptotrigona postica apresentou significativa ação frente ao HSV1- (98\% de redução da replicação) na quantificação do DNA viral em todas as condições e concentrações testadas da própolis, como ainda na microscopia eletrônica, no qual as imagens não demostraram partícula ou o complexo da replicação viral. No presente trabalho também se avaliou própolis de abelhas melíponas (jataí - T. angustula), frente a vírus DNA (BoHV-1) e RNA (BVDV). Entretanto, os melhores resultados obtidos da amostra foram frente ao vírus RNA (BVDV), quando se fez a inoculação prévia em células MDBK $(0,39 \mu \mathrm{g} / \mathrm{mL})$ do extrato hidroalcoólico, com $50 \%$ de viabilidade celular.

Yildirim et al. (2016) avaliaram a atividade antiviral de diferentes concentrações de Hatay Própolis (25, 50, $100,200,400 \mu \mathrm{g} / \mathrm{mL}$ ) frente a replicação do vírus herpes simplex tipo 1 (HSV-1) e tipo 2 (HSV-2) em células HEp-2 , e ainda o sinergismo entre a presença dos efeitos sinérgicos de própolis com Aciclovir ${ }^{\circledR}$ em 3 titulações de vírus diferentes $\left(1,10\right.$, e $\left.100 \mathrm{TCID}_{50}\right)$. A própolis demosntrou ser citotóxica nas concentrações 200 e $400 \mu \mathrm{g} / \mathrm{mL}$, enquanto que concentrações de Hatay própolis $25,50,100 \mu \mathrm{g} / \mathrm{mL}$ foram consideradas não tóxicas. Quanto ao efeito de própolis frente a replicação viral, obtiveram significativa supressão da replicação do HSV-1 e HSV-2 nas concentrações não tóxicas de 25,50 , e $100 \mu \mathrm{g} / \mathrm{mL}$ de própolis Hatay. Também encontraram diferentes tempos de inibição para os dois vírus. A amostra de própolis começou a inibir a replicação de HSV-1 após 24 h de incubação e, contra o HSV-2, após 48 h de incubação. Quanto o sinergismo da própolis e Aciclovir ${ }^{\circledR}$, o fármaco associado a própolis apresentou maior eficácia frente ao HSV-1 e HSV-2 do que isoladamente testado.

Amoros et al. (1992) avaliando a atividade virucida de própolis de abelha Apis mellifera, demonstraram a eficácia da ação de amostras distintas sobre Herpes Vírus tipo1 resistente a aciclovir, Herpes Vírus tipo 2, Vírus da Estomatite Vesicular, Adenovírus e vírus da doença de Newcastle. Ainda, os autores verificaram que o 3-Metil-2-butenil cafeato apresentou eficácia frente aos Herpes Vírus. Resultados distintos obtidos no presente estudo, uma vez que, a amostra da própolis que demosntrou ação virucida significativa, foi à própolis de abelhas meliponas, a jataí, e menor proporção à própolis marrom, de origem de abelha africani- zada. Ainda, o melhor resultado, constituiu frente ao BVDV, um vírus RNA, e não se obteve efeito frente ao BoHV-1.

Como pode ser visualizado nas Figuras 3C e 3D, o extrato de própolis de abelhas jataí apresentou atividade virucida ao BVDV nas duas temperaturas quando comparado aos controles negativos (PBS) e aos extratos de marrom e verde. A própolis de jataí demonstrou efeito virucida frente ao BVDV, após 24 horas de incubação. Quando o vírus e o extrato foram incubados a $22^{\circ} \mathrm{C}$, o título do vírus caiu de $(3,16 \log )$ para $(2,3 \log ) . \mathrm{A} 37^{\circ} \mathrm{C}$, a redução foi ainda mais pronunciada, $(3,5 \mathrm{log})$ para $(2,3 \mathrm{log})$. Além disso, após uma hora em contato com o vírus, a temperatura de $22^{\circ} \mathrm{C}$, esta amostra permitiu uma redução de $(2,1 \log )$ sugerindo que esta amostra foi efetiva já com pouco tempo de incubação. 0 extrato de própolis marrom, a $22^{\circ} \mathrm{C}$ também resultou em queda no título viral, de $(4,58)$ para $(3,75 \log )$ A própolis verde, no entanto, independente da temperatura avaliada, não demonstrou efeito virucida. Apesar de avaliarem-se duas temperaturas de incubação $\left(22^{\circ} \mathrm{C}\right.$ e $\left.37^{\circ} \mathrm{C}\right)$, não se observou diferença nos títulos que possa ser atribuída a este parâmetro, uma vez que em ambos os casos o decréscimo dos títulos virais seguiu uma mesma tendência.

A ação pronunciada da própolis de jataí frente ao BVDV, em relação aos demais extratos avaliados, pode estar relacionada à constituição química desta amostra, bem como a características do próprio vírus. 0 genoma do BVDV consiste uma fita simples de RNA, envolto por um envelope lipídico, o que se constitui numa diferença estrutural em relação ao BoHV-1, que é um vírus DNA. Este fato pode ter determinado a maior sensibilidade deste vírus à ação virucida do extrato de jataí (Cueto et al. 2011).

A atividade virucida da própolis foi avaliada por Vynograd et al. (2000), comparando-a ao Aciclovir ${ }^{\circledR}$ para o tratamento de Herpes genital. Na análise química da própolis identificaram como compostos majoritários, a galangina e a crisina. Como resultados, encontraram a maior eficácia da própolis quando comparada ao antimicrobiano comercial em reduzir as lesões e sintomas locais. No entanto, os valores encontrados no presente estudo, são distintos, onde para o Herpes Vírus, o extrato que apresentou melhor eficácia foi à amostra verde.

Os compostos majoritários descritos anteriormente como virucidas (Galangina e crisina), da mesma forma foram encontrados na amostra de abelhas jataí, embora os autores tenham avaliado frente a Herpes, no presente estudo houve expressiva atividade frente ao BVDV.

\section{CONCLUSÕES}

Os três extratos de própolis utilizados no presente estudo, quando avaliados frente ao BoHV-1 e BVDV, apresentaram significativa atividade antiviral e virucida.

Pode se observar semelhança qualitativa e variação na quantidade dos compostos químicos dos extratos de própolis avaliados.

Atividade inibitória dos extratos de própolis frente ao BVDV e BoHV-1 sugere a utilização destes como alternativas naturais ao uso de produtos comerciais, no combate a infecções por estes micro-organismos de importância em Medicina Veterinária. 


\section{REFERÊNCIAS}

Akao Y., Maruyama H., Matsumoto K., Ohguchi k., Nishizawa K., Sakamoto T., Araki Y., Mishima S. \& Nozawa Y. 2003. Cell growth inhibitory effect of cinnamic acid derivatives from propolis on human tumor cell lines. Biol. Pharm. Bull. 26:1057-1059.

Amoros M., Sauvager F. \& Girre L. 1992. In vitro antiviral activity of propolis. Apidologie 23(3):231-240.

Bastos E.M.A.F., Galbiati C., Loureire M. \& Scoaris D.O. 2011. Indicadores físico-químicos e atividade antibacteriana de própolis marrom frente à Escherichia coli. Arq. Bras. Med. Vet. Zootec. 63(5):1255-1259.

Bankova V. \& Marcucci M.C. 2000. Standardization of propolis: present status and perspectives, Bee World 81(4):182-188.

Bankova V.S., Christov R., Marcucci M.C. \& Popov S. 1998. Constituents of Brazilian geopropolis. Z Naturforsch. 53:402-406.

Bankova V., Galabov A.S., Antonova D., Vilhelmovan X.X. \& Di Perric B. 2014. Chemical composition of Propolis Extract $\mathrm{ACF}^{\circledR}$ and activity against herpes simplex virus. Phytomedicine. 21:1432-1438.

Cabral I.S.R., Oldoni T.L.C., Prado A., Neves R.M., Bezerra R.M.N. \& Alencar S.M. 2009. Composição fenólica, atividade antibacteriana e antioxidante da própolis vermelha Brasileira. Química Nova 32(6):1523-1527.

Choudhari M.K., Punekar S.A., Ranade R.V. \& Paknikar K.M. 2012. Antimicrobial activity of stingless bee (Trigona sp.) propolis used in the folk medicine of Western Maharashtra, India. J. Ethnopharmacol. 14(1):363-367.

Coelho G.R., Mendonça R.Z., Vilar K. de S., Figueiredo C.A., Badari J.C., Taniwaki N., Namiyama G., Oliveira M.I., Curti S.P., Silva P.E. \& Negri G. 2015. Antiviral Action of Hydromethanolic Extract of Geopropolis from Scaptotrigona postica against Antiherpes Simplex Virus (HSV-1). J. Evid. Based Complement. Altern. Med. 2015:1-10.

Cueto A.P., Alves S.H. \& Pilau M. 2011. Atividade antiviral do extrato de própolis contra o Calicivírus felino, adenovírus canino 2 e vírus da Diarréia viral bovina. Ciência Rural 41(10):1800-1806.

Duran N., Muz M. \& Culha G. 2011. GC-MS analysis and antileishmanial activities of two Turkish propolis types. Parasitol Res. 108(1):95-105.

Fischer G., Cleff M. B., Dummer L.A., Paulino N., Paulino A.S., Vilela C.O., Campos F.S., Storch T., Vargas G.D’A., Hübner S.O. \& Vidor T. 2007. Adjuvant effect of green propolis on humoral immune response of cattle immunized with bovine herpesvirus type 5 . Vet. Immunol. Immunopathol. 116:79-84.

Gekker G., Hu S., Spivak M., Lokensgard J.R. \& Peterson P.K. 2005. Anti-HIV-1 activity of propolis in CD4+ lymphocyte and microglial cell cultures. J Ethnopharmacol. 102:158-163.

Gilberto C., Franchi J.R., Cleber S., Moraes V.C., Toreti A., Daugsch A., Nowill A.E. \& Park Y.K. 2012. Comparison of effects of the ethanolic extracts of Brazilian propolis on human leukemic cells as assessed with the MTT Assay. J. Evid. Based Complement. Altern. Med. 2012:303-309.

Gressler L.T., Da Silva A.S., Machado G., Rosa L.D., Dorneles F., Gressler L.T., Oliveira M.S., Zanette R.A., De Vargas A.C. \& Monteiro S.G. 2012. Susceptibility of Trypanosoma evansi to propolis extract in vitro and in experimentally infected rats. Res. Vet. Sci. 93:1314-1317.
Jug M., Koncic M.Z. \& Kosalec I. 2014. Modulation of antioxidant, chelating and antimicrobial activity of poplar chemo-type propolis by extraction procures. LWT - Food Science and Technology 57:530-537.

Kujumgiev A. 1999. Antibacterial, antifungal and antiviral activity of propolis of different geographic origin. J. Ethnopharmacol. 64(3):235240.

Ma X., Guo Z., Shen Z., Liu Y., Wang J. \& Fan Y. 2015. The anti-porcine parvovirus activity of nanometer propolis flavone and propolis flavone in vitro and in vivo. J. Evid. Based Complement. Altern. Med. 2015:1-11.

Mayr A., Bachmann P.A., Bibrack B.M. \& Withmann G. 1982. Virologische Arbeitsmethoden - Band IV - Sicherheit bei virologischen arbeiten - Biometrische Methoden. Gustav Fischer Verlag, Stuttgart.

Mossmann T. 1983. Rapide colorimetric assay for cellular growth and survival: application to proliferation and cytotoxicity assays. J. Immunol. Methods 65(1/2):55-63.

Paulino P., Scrimim F.M., Raichaski L.B., Marcucci M.C., Scremim A.C. \& Calixto J.B. 2002. Mechanisms involved in the relaxant action of the ethanolic extract of propolis in the guinea-pig trachea in vitro. J. Pharm. Pharmacol. 54:845-852.

Pereira A.S., Seixas F.R.M.S. \& Aquino Neto F.R. 2003. Própolis: 100 anos de pesquisa e suas perspectivas futuras. Química Nova 25:321-326.

Pinto M.S., Faria J.E., Message D., Cassini S.T.A., Pereira C.S. \& Gioso M.M. 2001. Efeito de extratos de própolis verde sobre bactérias patogênicas isoladas de leite de vacas com mastite. Braz. J. Vet. Res. Anim. Sci. 38:278-283.

Ortega N.S., Campo N.B. \& Cabezas-Fajardo F.A. 2011. Actividad antibacteriana y composición cualitativa de propoleos provenientes de zonas climáticas del Departamento del Cauca. Artículos de Investigación Científica y Tecnológica 9(1):8-16.

Reed R.H. \& Muench H. 1938. A single method of estimating fifty percent end points. Am. J. Trop. Med. Hyg. 27:493-497.

Sawaya A.C.H.F., Tomazela D.M., Cunha I.B.S., Bankova V.S., Marcucci M.C., Custódio A.R. \& Eberlin M.N. 2004. Electrospray ionization mass spectrometry fingerprinting of propolis. Analyst 129:739-744.

Sawaya A.C.H.F., Calado J.C.P., Santos L.C., Marcucci M.C., Akatsu I.P., Soares A.E.E., Abdelnur P.V., Cunha I.B.S.C. \& Eberlin M.N. 2009. Composition and antioxidant activity of propolis from three species of Scaptotrigona stingless bees. J. ApiProduct. ApiMedical Sci. 1:37-42.

Salomão K., Pereira P.R.S., Campos L.C., Borba C.M., Cabello P.H., Marcucci M.C. \& Castro S.L. 2008. Brazilian Propolis: correlation between chemical composition and antimicrobial activity. eCAM 5(3).

Schnitzler P. 2010. Antiviral activity and mode of action of propolis extracts and selected compounds. Phytother. Res. 24(1):20-28.

Vynograd N., Vynograd I. \& Sosnowski Z. 2000. A comparative multi-centre study of efficacy of propolis, acyclovir and placebo in the treatment of genital herpes (HSV). Phytomedicine 7(1):1-6.

Yildirim A., Duran G.G., Duran N., Jenedi K., Bolgul B.S., Miraloglu M. \& Muz M. 2016. Antiviral activity of Hatay Propolis against replication of Herpes Simplex Virus Type 1 and Type 2. Med. Sci. Monit. 22:422-430. 